\title{
Professional paper
}

\section{DIFFERENCES IN SITUATIONAL EFFICIENCY OF GOALKEEPERS DEPENDING ON MATCH OUTCOME BASED ON CHAMPIONS LEAGUE SEMI FINALS AND FINALS ${ }^{1}$}

\author{
UDC: 796.332 .054 .23 \\ 796.332.012.11-053.5 \\ https://doi.org/10.18485/snip.2021.11.1.en.6 \\ Borko Katanić \\ Faculty of Sports and Physical Education in Nikšić, \\ University of Montenegro, Podgorica, Montenegro \\ Ana Nikolić3 \\ Faculty of Sports and Physical Education, University of Niš, Serbia \\ Predrag Ilić ${ }^{4}$ \\ Faculty of Sports and Physical Education, University of Niš, Serbia \\ Mima Stanković \\ Faculty of Sports and Physical Education, University of Niš, Serbia \\ Manja Vitasović \\ Equestrian Club “Gorska Team”, Belgrade, Serbia
}

\begin{abstract}
The aim of this paper is to determine the differences in situational performance of football goalkeepers depending on the outcome of the match, based on the semi-final and final matches of the Champions League, using the method of comparative analysis of the manifestation of goalkeeper's tactical elements. The analysis was conducted in the semi-final and final matches of the Champions League in the 2016/2017 football season. The paper analyzes the situational elements of the goalkeepers' techniques in the Champions League finals. For the purpose of the research, an observation sheet was formed based on the previous research and personal experience of the author, which was entered into the application "Dartfish EasyTag". Twenty variables were entered into the observation sheet, which are classified into the goalkeeper's defensive and offensive elements. Video games were downloaded from the Internet, and the analysis was carried out with the help of a portable device, in the "Dartfish EasyTag" application. The results obtained were processed by means of descriptive statistics - total value and difference. After the complete survey, the number of overall situational activities of the goalkeeper is not dependent on the outcome of the match.
\end{abstract}

Key words: game analysis, goalkeeper, situational defensive elements, soccer

\footnotetext{
Paper received: 25 June 2020, edited: 28 October 2020, accepted for publication: 1 November 2020

$2 \bowtie$ borkokatanic@gmail.com

3 Ana Nikolić holds a MA degree in sports and physical education, obtained at the Faculty of Sports and Physical Education, at the University of Niš.

4 Predrag Ilić is a PhD student at the Faculty of Sports and Physical Education, University of Niš.

5 Mima Stanković is a PhD student at the Faculty of Sports and Physical Education, University of Niš.
} 


\section{INTRODUCTION}

Football has been the most popular sports game in the world for decades now (Samardžić, 2014). The reasons for football's popularity should be looked for in the content of the game, the fact that it is adapted to humans and their pronounced need to play. Football is considered to be an extremely complex sport and the results achieved depend on many factors. Coaches try to "control" these factors as much as possible. In order to achieve the highest possible impact on the factors that football results depend on, a coach must analyze, detect and use the information obtained (Vujović et al., 2013). With progress and implementation of science in sports, alongside the appearance of contemporary training techniques, and the use of information systems in sports, the need to quantify the football game has been more pronounced in morphological, motoric, functional, bio mechanic and specific psychological sense alike, but also in terms of technical and tactical aspects of the game (Williams \& Hodges, 2005). During the last two decades, there has been a significant increase in the interest into the analysis of football matches. Match analysis is frequently used in many sports and is considered to be a vital process that enables coaches to obtain objective information that can be used in improving performance (Castellano et al., 2012). The goals of monitoring the competitor's activities and collecting data that are important for the play of a team are achieved using the method of notation (Armatas et al., 2009; Basic et al., 2015). Talovic et al. (2011) point out that notational analysis is an objective method of gathering information where key parts of the performance can be assessed in a consistent and reliable manner. Reilly et al. (2000) stipulate that, by following and analyzing situations in a football match, it is possible to notice various factors of the football game and characteristics of elite football players. Also, Franks \& Miller (1991) came to the conclusion that football coaches tended to be less than $45 \%$ right in their assessments of what has happened during 45 minutes of the match, which indicate that it is essential to analyze matches in modern football.

It is very important to analyze the change in goalkeepers in parallel with the change of the game system and the incoming influence of science. Initially, the goalkeeper's aim was to prevent the ball from enter their goal and so the goalkeepers were strictly standing on their goal line, while their defense was reduced to attempting at defense by means of quick reaction, catching and parades. Therefore, they did not participate in other tasks. Later on, goalkeepers started securing not only the goal, but also the $5 \mathrm{~m}$ perimeter around it with occasional participation in other tactical tasks as well. Goalkeepers nowadays defend in a more modern way, they are a personification of intelligence, reliable in counter-attack at the opponent, and they are the masters in starting an attack for their own team (Dakić, 2012). The role of a goalkeeper is not only the most important one, but it also entails significantly more responsibilities than other roles. The delicacy of a goalkeeper's role reflects in their very active participation in the game, as they are the ones to command the defense, to start an attack and to provide the psychological tone of the game. Also, goalkeepers' role in contemporary football has a wider impact on the game, because they are increasingly becoming field players, which also requires additional training. Upon the introduction of the rule that the ball returned to the team's goalkeeper cannot be caught by hands, it became obvious that goalkeepers' technical knowledge and develop additional skills both during a game and in a training session needs to be improved. This new knowledge has to be learned and developed in every training session. This means that, in addition to working on specific techniques and tactics, goalkeepers also have to devote a part of their training to ball shooting, ball leading with one and both legs, and dribbling (Samardžić, 2014).

Presented studies indicate the necessity of analyzing matches in modern football. The aim of this study is to detect the differences in terms of situational success based on the match results of the Champions Leagues semifinal and final matches.

\section{METHODOLOGY}

The video material was collected from the internet. The ideo analysis was conducted using PC, while data collection was conducted using the Dartfish EasyTag application, installed on a portable device. This app has a wide application in sports analysis and is used for analysis of competitive and training activities in different sports. Observance protocol was formed prior to the match analysis. Such protocol was transferred to the app. Notational system within the app was used for recording every action of goalkeepers.

The sample consisted of the following goalkeepers: Bufon (Juventus), Subašić (Monaco), Navas (Real Madrid) and Oblak (Atletico Madrid), all participants of the semi-finals and finals of the 2017 Champions League. Results 44 
were presented for each goalkeeper separately during the 5 matches, which comprises a total of 10 analyses. The results were presented in the following order:

Real Madrid - Atletico Madrid 3:0 (Navas - Oblak)

Atletico Madrid - Real Madrid 2:1 (Oblak - Navas)

Monaco - Juventus 0:2 (Subašić - Buffon)

Juventus - Monaco 2:1 (Buffon - Subašić)

Juventus - Real Madrid 1:4 (Buffon - Navas)

All goalkeepers' defensive and offensive actions were analyzed. Notational system was used to detect each activity of the goalkeepers in the "Dartfish Easytag" app. A total of 20 variables was monitored, namely the 20 situational elements in the goalkeepers' play that were selected for the purpose of this study based on the previous research studies.

The situational elements of goal defense are:

1. NAR- near angle shot stopping

2. MGS - middle goal shot stopping

3. FAS - far angle shot stopping

4. DFC - defense from corner kicks

5. FKS - free kicks saves

6. D1:1 - defense from one to one situation

7. $\mathrm{CCH}$ - catching from crossing and high ball

8. $\mathrm{PCH}$ - punching from crossing and high ball

Situational elements of the goalkeepers' offence are:

9. HTD3 - hand throws in the defensive 3rd of the field

10. HTM3 - hand throws in the middle 3rd of the field

11. HTA3 - hand throws in the attacking 3rd of the field

12. PD3 - pass the ball in the defensive 3rd of the field

13. PM3 - pass the ball in the middle 3rd of the field

14. PA3 - pass the ball in the attacking 3 rd of the field

15. BPD3 - pass after back-pass from the defensive 3rd of the field

16. BPM3 - pass after back-pass from the middle 3rd of the field

17. BPA3 - pass after back-pass from attacking 3rd of the field

18. GD3 - goal-kick in the defensive 3rd of the field

19. GM3 - goal-kick in the middle 3rd of the field

20. GA3 - goal-kick in the attacking 3rd of the field

\section{RESULTS}

The paragraphs below show the results for each goalkeeper separately during the 5 matches of the Champions League semi-finals and finals (a total of 10 analyses). The results are presented in Table 1, in the following order:

Real Madrid - Atletico Madrid 3:0 (Navas - Oblak)

Atletico Madrid - Real Madrid 2:1 (Oblak - Navas)

Monaco - Juventus 0:2 (Subašić - Bufon)

Juventus - Monaco 2:1 (Bufon - Subašić)

Juventus - Real Madrid 1:4 (Bufon - Navas)

\section{DISCUSSION}

In comparative analysis of situational defense elements, presented in Table 1, it can be noticed that Navas had more activity - 13:6, and more goal defenses - 9:4. In regard to the offense actions, Navas had 26, compared to Oblak's 15. This data clearly indicates the higher activity of Navas in all game elements during the match. The highest value has been scored in the parameter - insertion of the ball from the 5 meter line into the maneuver zone, 7:5 for Navas. In this case, the goalkeeper of the winning team had more defensive as well as offensive actions. 


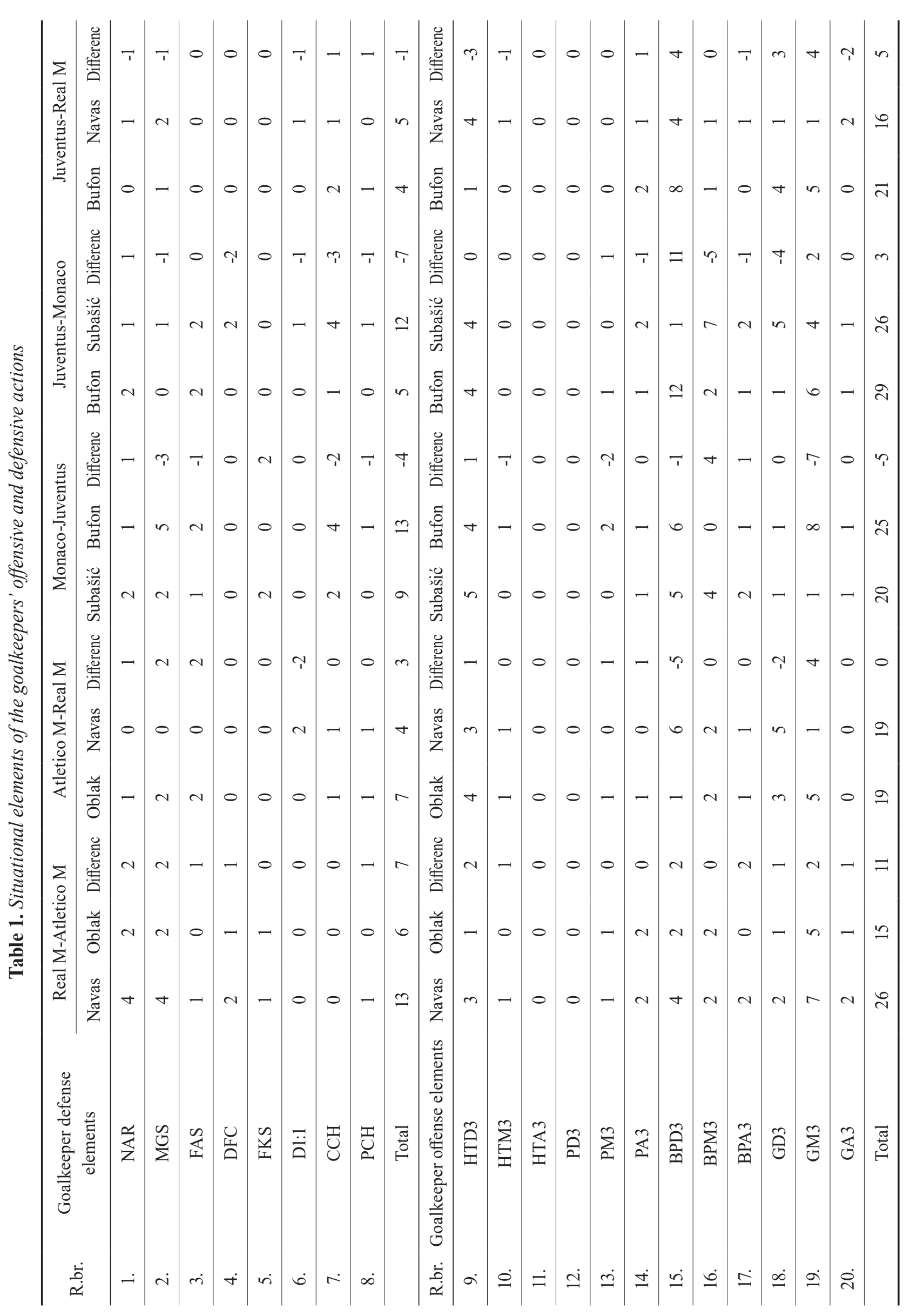


The situation changed in the revanche match. Navas had no defense, compared to Oblak's 5. Also, Oblak had a higher total of all defensive actions - 7:5. The number of offensive actions was equal 19:19. Out of that number, Oblak had the most insertions of the ball from the 5 meter line into the maneuver zone, a total of 5 times, while the highest number (6) of Navas' ball insertions was after a return pass from a teammate from the defense zone. This shows the high pressing of Atletico and the inability of Real players to get the ball through the maneuver zone. In this game, the goalkeeper of the winning team had more defensive actions, while the number of offensive actions was equal.

In the Buffon and Subašić duel, Buffon had significantly more interventions - 8:5, out of which 5 were from the middle of the goal. Also, he had a better score of defense actions 13:9, as well as interventions with deep balls - 5:2. The highest numbers of Buffon's offensive actions were insertions of the ball from the 5 meter line into the maneuver zone - 8, even though this could be considered more of a parameter of the team's tactical game style, than as an individual characteristic. Similar can be considered for the high number of throw- ins into the defense third of the terrain- 5:4 for Subašić, which can also be related to the coach's tactical requests. A high number of ball insertions after a teammate's return pass from the defense zone can be noticed - 6:5 for Buffon, but this data mainly shows the high pressing of the opponent and the inability of the maneuver players to find a solution for it, therefore, being forced to return the ball to their goalkeeper. The goalkeeper of the winning team scored more offensive and defensive actions.

In the revanche match, Subašić had a higher total number of defensive interventions, compared to Buffon12:5. The highest number of interventions were on center shots and deep balls - 4. The offense elements were pretty much equal, with Buffon scoring 29 and Subašić 26 actions. Buffon was predominant in long passes after a teammate's return pass from the defense zone, a total of 12 times, compared to Subašić's 1 action. This data shows that Juventus was safekeeping the advantage from the first match without offensive ambitions. Also, the data for goal-kicks from the 5 meter line in the attack zone 6:4 (for Bufon), as well as goal-kicks from the 5 meter line in the defense zone - 5:1 for Subašić, reflects the team's manner of playing. Namely, it is clear that Monaco, through organized offense game, tried to reach the goal of Juventus, while the home players tried to maintain the advantage achieved in the first match.

During the observation of defense elements during the finals, a low number of the named elements was noticed - 5:4, for Navas, which is an indicator of a very closed play. Namely, both teams used defensive game in the final match, with the aim to reduce the number of errors, and not to risk with the offense actions, but to safeguard their own goal while waiting for the opponent to make a mistake. On the other hand, Buffon had 21 offence activities, compared to Navas's 16. Buffon's dominant activities were: long passes after a teammate's return pass in the defense zone - 8; goal-kicks from the 5 meter line in the maneuver zone - 5 and in the defense zone - 4. Navas had 4 times both of the following actions: throw-ins of the ball in the defense third of the court, as well as long passes after a teammate's return pass in the defense zone. The goalkeeper of the winning team - Navas, achieved a somewhat higher number of offense actions, with a somewhat lower number of defense actions (4:5).

After the analysis of the situational elements of the goalkeepers' actions in all 5 matches, it can be noticed that in all the matches goalkeepers had more offense than defense actions, with the relation of 12:8 for the offense actions, but also bearing in mind the choice of the defense and offense variables.

The following activities were considered predominant:

1. Long pass after a teammate's return pass in the defense zone

2. Goal-kicks from the 5 meter line in the maneuver zone

3. Throw-ins of the ball in the defense third of the field

4. Long pass after a teammate's return pass in the maneuver zone

Therefore, the findings of this research are in line with the findings of Dakic (2012), who also segregated defense actions as predominant activities of goalkeepers. In his studies, it was concluded that goalkeepers forward the ball to their teammates 29 times per match on average, which is close to the findings in this paper. Also, the balls were mainly forwarded to the teammates in the defense and maneuver zone, which is in line with the results of this research. Nevertheless, it must be stipulated that this data refers more to the game style and tactical tasks of the team, than of the success of the goalkeepers.

In this paper, 3 out of 4 predominant activities of the goalkeepers were activities conducted by legs: long passes after a teammate's return pass in the defense zone, goal-kicks from the 5 meter line in the maneuver zone and long passes after a teammate's return pass in the maneuver zone. The importance of the leg game was stipulated by Janković et al. (2015). They concluded that it represents a crucial and predominant aspect of the game 
of contemporary goalkeepers, because in this way they significantly participate in the beginning and organization of their team's offense actions. Sainz De Baranda et al. (2008) came up with different results. Namely, the most frequently used game elements of goalkeepers, according to them, were defense elements, followed by ball control and passes. Therefore, according to their papers, goalkeepers performed a greater number of defense than offense actions.

By summarizing the analysis of the goalkeepers' mutual duels, it has been identified that neither the total number of the goalkeepers' activities, nor the number of defense actions depend on the match outcome. The only connection was found between the goalkeepers' offense activities and the results. Namely, the goalkeepers of the winning teams had a higher number of offense actions in all matches, even though this data is not in line with the results obtained by Sainz De Baranda et al. (2008). Therefore, the results of this research should be taken with a grain of salt, because certain offense variables are related to return balls from a teammate in the defense and maneuver zone, as well as to punting in the middle and offense field zone. The given variables represent the game style, especially after being in the lead, when the game concept of the team changes, as the team aims to maintain the favorable result. Regarding defense activities, as well as the total number of activities and their connection with the achieved results, it should be stipulated that significant differences have been found, where the goalkeeper of the winning team in one match had many defense activities, and in the second one half less. The same goes for the total number of activities.

\section{CONCLUSION}

The role of a goalkeeper is not only the most important of all the team players, but also bears higher responsibility. The delicacy of the role is reflected in the facts that they have to participate in the game very actively, to command the defense, to start the offense and to give psychological tone to the game. The role of a goalkeeper in contemporary football has a wider impact on the game because they have become more of a field player, which also requires additional training. This means that, in addition to working on the development of a specific technique and tactical characteristic for goalkeepers, they also have to dedicate a part of each training to the technique of ball shooting, ball leading with both legs and dribbling.

With progress and implementation of science in sports, alongside the appearance of contemporary training techniques, and the use of information systems in sports, the need to quantify the football game has been more pronounced in morphological, motoric, functional, bio mechanic and specific psychological sense alike, but also in terms of technical and tactical aspects of goalkeepers' play. Certain authors claim that by monitoring and analyzing the situations in a football match, it is possible to notice various factors and characteristics of elite football players.

Upon the analysis of the situational elements of the goalkeepers' game in all 5 matches, it can be noticed that in all the games the goalkeepers performed more offensive than defensive activities.

The following activities were co nsidered predominant:

1. Long passes after a teammate's return pass in the defense zone

2. Goal-kicks from the 5 meter line in the maneuver zone

3. Throw-ins of the ball in the defense third of the field

4. Long passes after a teammate's return pass in the maneuver zone

Therefore, it can be noticed that all the listed activities are offense ones. Nevertheless, it must be stipulated that this data refers more to the team's playing style and tactical tasks, than to the success of goalkeepers.

By summarizing the analysis of goalkeepers' mutual duels, it has been identified that neither the total number of goalkeepers' activities, nor the number of defense actions depend on the match outcome. The only connection found was between the offense activities of the goalkeepers and the results. Namely, the goalkeepers of the winning teams had a higher number of offense actions in all the matches. Nevertheless, the results of this research should be taken with a grain of salt, because certain offense variables are related to returning the ball from the teammate in the defense and maneuver zone, as well as to punting in the middle and offense field zone. The given variables represent the game style, especially after being in the lead, when the game concept of the team changes, as the team aims to maintain the favorable result. Regarding defense activities, as well as the total number of activities and their connection with the achieved results, it should be stipulated that significant differences have been found, where the goalkeeper of the winning team in one match had many defense activities, and in the second one half less. The same goes for the total number of activities. 
For obtaining more complete results on the impact of implementing the situational elements of goalkeepers' activities on match results, a more detailed research should be conducted. Namely, it is necessary to conduct the analysis of goalkeepers' activities on a larger sample of matches, in order to reach more comprehensive conclusions.

\section{REFERENCES}

1. Armatas, V., Yiannakos, A., Zaggelidis, G., Skoufas, D., Papadopoulou, S. \& Fragkos, N. (2009). Differences in offensive actions between top and last team in Greek first soccer division. A retrospective study 1998-2008. Journal of Physical Education and Sport, 23(2), 1-5.

2. Bašić, D., Barišić, V., Jozak, R. \& Dizdar, D. (2015). Notacijska analiza nogometnih utakmica. Zagreb: Leonardo Media.

3. Castellano, J., Casamichana, D. \& Lago, C. (2012). The use of match statistics that discriminate between successful and unsuccessful soccer teams. Journal of human Kinetics, 31, 139-147.

4. Dakić, M. (2012). Analiza učinka golmana fudbalskih timova učesnika završnice Lige šampiona u sezoni 2011/2012. (Završni rad). Beograd: Fakultet sporta i fizičkog vaspitanja.

5. Franks, M. \& Miller G. (1991). Training coaches to observe and remember. Journal of sports sciences, 9, 285-297.

6. Janković, A., Leontijević, B., Cvijanović, B. \& Mićanović, N. (2015). Analysis of competitive application of elements of goalkeeper technique in football. Godišnjak Fakulteta sporta i fizičkog vaspitanja, (21), 21-29.

7. Reilly, T., Williams, A. M., Nevill, A. \& Franks, A. (2000). A multidisciplinary approach to talent indentification in soccer. Journal of Sports Sciences, 18(9), 695-702.

8. Sainz De Baranda, P., Ortega, E. \& Palao, J. M. (2008). Analysis of goalkeepers' defence in the World Cup in Korea and Japan in 2002. European Journal of Sport Science, 8(3), 127-134.

9. Samardžić, N. (2014). Violations of football goalkeeper depending on the characteristics of the training process. Godišnjak Fakulteta sporta i fizičkog vaspitanja, (20), 113-127.

10. Talović, M., Fiorentini, F., Sporiš, G., Jelešković, E., Ujević, B. \& Jovanović, M. (2011). Notacijska analiza u nogometu. Sarajevo: Fakultet sporta i tjelesnog odgoja Sveučilišta u Sarajevu.

11. Vujović, P., Stupar, D. \& Radoman, M. (2013). The determinants of the efficiency of shots on goal at the world cup in South Africa 2010. TIMS. Acta, 7(2), 115-125.

12. Williams, A. M. \& Hodges, N. J. (2005). Practice, instruction and skill acquisition in soccer: Challenging tradition. Journal of sports sciences, 23(6), 637-650. 